九州大学学術情報リポジトリ

Kyushu University Institutional Repository

\title{
Molecular design of hole transport materials for obtaining high durability in organic electroluminescent diodes
}

Adachi, Chihaya

Chemical Products R\&D Center, Ricoh Co., Ltd.

Nagai, Kazukiyo

Chemical Products R\&D Center, Ricoh Co., Ltd.

Tamoto, Nozomu

Chemical Products R\&D Center, Ricoh Co., Ltd.

http://hdl. hand le. net/2324/19442

出版情報: Applied Physics Letters. 66 (20)，pp.2679-2681，1995-05-15. American Institute of Physics

バージョン :

権利関係: Copyright 1995 American Institute of Physics. This article may be downloaded for personal use only. Any other use requires prior permission of the author and the American Institute of Physics. 


\title{
Molecular design of hole transport materials for obtaining high durability in organic electroluminescent diodes
}

\author{
Chihaya Adachi, ${ }^{a)}$ Kazukiyo Nagai, and Nozomu Tamoto \\ Chemical Products R\&D Center, Ricoh Co., Ltd., 146-1 Nishisawada, Numazu-shi, Shizuoka 410, Japan
}

(Received 19 December 1994; accepted for publication 20 March 1995)

\begin{abstract}
The molecular design of hole transport materials (HTMs) for producing high durability in organic layered electroluminescent (EL) diodes was elucidated. The durability tests were examined using fourteen hole transport materials in the cell structure of an anode/hole transport layer (HTL)/emitter layer (EML)/cathode. The ionization potential (Ip) of HTLs was found to be the dominant factor for obtaining high durability in organic EL devices. The formation of the small energy barrier at the interface of a HTL/anode was required for high durability. Moreover, no straightforward relations between melting point, glass transition temperature of the HTMs, and durability of the EL devices were observed. The EL device using the HTM having a low Ip $(5.08 \mathrm{eV})$ showed an especially remarkable stability. In this case, the half-life period of the initial luminance was beyond $500 \mathrm{~h}$.

(C) 1995 American Institute of Physics.
\end{abstract}

After Tang's report on the multilayered organic electroluminescent (EL) diode, ${ }^{1}$ the development of organic EL devices focused on the optimization of cell structures for obtaining high luminance ${ }^{2,3}$ and the development of organic materials for obtaining a wide variety of emission colors. ${ }^{4-7}$ Concerning the optimization of EL cell structures, three types of EL cell structures were proposed. ${ }^{8}$ Using various kinds of EL cell structures, a variety of fluorescent dyes could be used for emitter materials. The key point for obtaining high luminance was found by controlling the movement of charge carriers and molecular excitons and to realizing the confinement in the emitter layers. A variety of emission colors were also obtained by the doping of highly fluorescent molecules into the host emitter layers based on the idea of a host-guest system. ${ }^{9,10}$ Thus, it was revealed that the organic EL devices possess high quantum efficiency (3\%) and high energy conversion efficiency $(10 \mathrm{~lm} / \mathrm{w})$ with various emission colors. ${ }^{11}$

From a practical point of view, another significant subject is to increase the durability of the EL devices. There have been several studies on EL devices with the aim of achieving high durability under continuous operation. In particular, VanSlyke demonstrated the insertion of a phthalocyanine layer between an anode/HTL interface, which resulted in a significant improvement in durability. ${ }^{12}$ Recently, Shirota demonstrated that the multilayered EL device consisting of double hole transport layers of triphenylamine derivatives exhibits significant durability. ${ }^{13}$ At this stage, however, the factors affecting the durability of the EL devices remained uncertain.

In this study, we focused on the energy barrier of hole injection and examined the durability tests using fourteen hole transport materials (HTMs) in the cell structure of an anode/hole transport layer (HTL)/emitter (EML)/cathode. We also measured the ionization potential (Ip) of the HTLs and the melting point $\left(\mathrm{T}_{\mathrm{m}}\right)$ and glass transition temperature $\left(\mathrm{T}_{\mathrm{g}}\right)$ of the HTMs. We mention the molecular design of

${ }^{a)}$ Electronic mail: jbc0167@niftyserve.or.jp
HTMs for obtaining high durability in organic EL diodes.

Figure 1 shows the EL cell structure used in this study. In Fig. 1 the organic materials, the HTMs, and the emitter material are also shown. We used fourteen aromatic amines as the HTL and tris(8-quinolinolato) aluminum as an emitter. Organic layers were deposited on a precleaned indium-tinoxide (ITO) glass substrate and a cathode MgAg alloy (10:1, atomic ratio) layer was deposited on an EML by codeposition in a $6 \times 10^{-6}$ Torr vacuum at room temperature. The thickness of the ITO layer was $1700 \AA$ and the sheet resistance was about $20 \Omega / \square$ (Asahi Glass Co., Ltd. sputtered film). The deposition rate for organic layers was about $2 \AA / s$. The thickness of the organic layers was fixed at $500 \AA$. The durability tests were performed under the nitrogen atmosphere at a constant current density of $J=30 \mathrm{~mA} / \mathrm{cm}^{2}$. The luminance was measured with a luminance meter, Topcom BM-7. The ionization potential of the organic layers and an ITO layer was determined using a Riken-Keiki AC-1. The thermal analysis of the HTMs was measured using a Rigaku TAS100.

Table I summarizes the durability characteristics (initial luminance, and luminance after 10, 100, and $500 \mathrm{~h}$ ) of EL cells with fourteen HTMs. In each EL device, the light emission gradually decreased with time, and the durabilities depended on the chemical structures of the HTMs. In particular, excellent performance was obtained using the HTM1 and HTM10. In the HTM1, the initial luminance was 790 $\mathrm{cd} / \mathrm{m}^{2}$ and the luminance of a $438 \mathrm{~cd} / \mathrm{m}^{2}$ was still maintained after $500 \mathrm{~h}$ of continuous operation. Also, similar result was obtained in the HTM10. On the contrary, the half-life period of the initial luminance was less than $10 \mathrm{~h}$ in the HTM3, HTM4, HTM5, and HTM11. Furthermore, the time for the half-decay of the luminance was a few hours in the HTM2, HTM6, HTM7, HTM8, HTM9, HTM13, and HTM14.

Figure 2 shows the relation between the ionization potential of the HTLs and $L_{10} / L_{0} . L_{0}$ denotes the initial luminance and $L_{10}$ indicates the luminance maintained after $10 \mathrm{~h}$ of continuous operation. Thus, a large $L_{10} / L_{0}$ value expresses high durability of the EL devices. Though the Ip of HTLs ranged widely from 5.0 to $5.8 \mathrm{eV}$ depending on the 


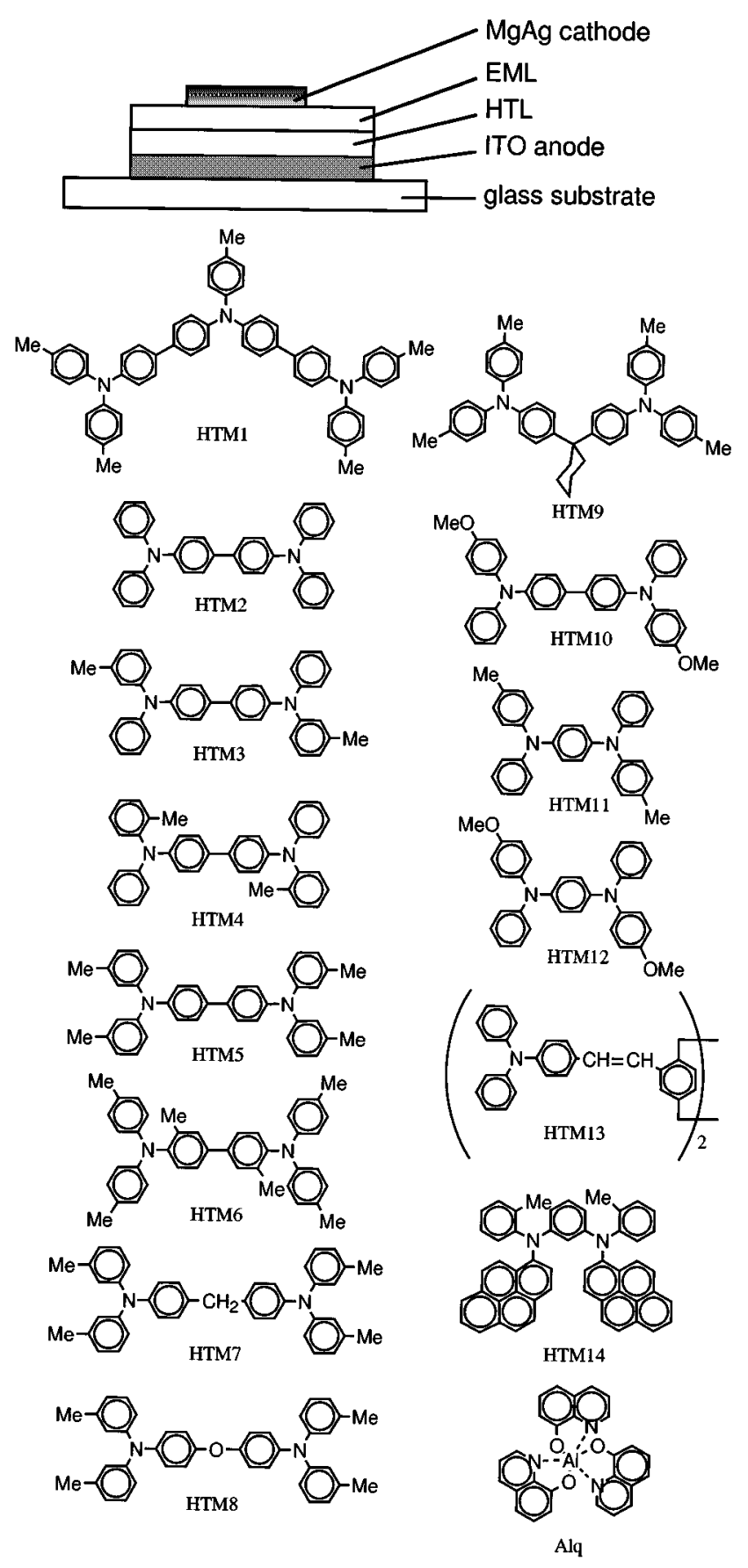

FIG. 1. The EL cell structure and fourteen hole transport and emitter materials used in this study.

substituent groups and the conjugated system of the HTMs, we can recognize that the durability of EL devices $\left(L_{10} / L_{0}\right)$ is closely related to the Ip of the HTLs. The HTL1 having a low Ip value $(5.08 \mathrm{eV})$ showed a high $L_{10} / L_{0}$ value, whereas HTL7 having a high Ip value $(5.60 \mathrm{eV})$ showed a low $L_{10} / L_{0}$ value. In addition, we observed that the initial voltage of each device was closely correlated with the Ip of the HTLs. The HTL having a low Ip value resulted in a low initial driving voltage. Thus, we can recognize that the formation of the small energy barrier for hole injection at the interface of an ITO/HTL resulted in high durability and low drive voltage, because the Ip of the ITO layer used in this
TABLE I. The initial luminance $L_{0}$, initial voltage $\left(V_{0}\right)$, and the luminance after 10,100 , and $500 \mathrm{~h}$ of continuous operation $\left(L_{10}, L_{100}, L_{500}\right)$ in the fourteen EL devices.

\begin{tabular}{cccccc}
\hline \hline & Initial luminance & Initial voltage & \multicolumn{3}{c}{ Luminance/cd/m } \\
HTM & $L_{0} / \mathrm{cd} / \mathrm{m}^{2}$ & $V_{0} / V$ & $L_{10}$ & $L_{100}$ & $L_{500}$ \\
\hline 1 & 790 & 8.1 & 547 & 476 & 438 \\
2 & 790 & 10.6 & 260 & $\ldots$ & $\ldots$ \\
3 & 920 & 13.7 & 350 & 180 & $\ldots$ \\
4 & 860 & 12.2 & 390 & 250 & $\ldots$ \\
5 & 790 & 12.3 & 343 & 140 & $\ldots$ \\
6 & 1240 & 12.0 & 300 & $\ldots$ & $\ldots$ \\
7 & 276 & 18.0 & 0 & $\ldots$ & $\ldots$ \\
8 & 350 & 15.3 & 18 & $\ldots$ & $\ldots$ \\
9 & 750 & 11.7 & 38 & $\ldots$ & $\ldots$ \\
10 & 685 & 9.6 & 433 & 310 & 200 \\
11 & 470 & 9.3 & 250 & $\ldots$ & $\ldots$ \\
12 & 157 & 8.0 & 133 & $\ldots$ & $\ldots$ \\
13 & 566 & 15.8 & 164 & 94 & $\ldots$ \\
14 & 600 & 11.8 & 48 & $\ldots$ & $\ldots$ \\
\hline \hline
\end{tabular}

experiment was $5.0 \mathrm{eV}$ and the Ip of the Alq emitter layer was $5.7 \mathrm{eV}$.

We also must take into account the thermal characteristics of the HTMs for the discussion of durability. As all HTMs used in this experiment form amorphous films by vacuum deposition, the gradual growth of crystallites in an amorphous film induced by joule heat are thought to be one of the important degradation factors. Figure 3 shows the relation between the $L_{10} / L_{0}$ term and the $T_{m}$ of the HTMs, and Fig. 4 shows the relation between the $L_{10} / L_{0}$ term and the $T_{g}$ of the HTMs. However, in each case, we observed no direct relationships between $L_{10} / L_{0}$ and the thermal characteristics. Thus, simple improvement in the thermal properties of the HTMs is insufficient to enhance the durability of the EL devices.

We will now discuss one of the possible degradation mechanisms. When a large energy barrier of hold injection at the interface of the ITO/HTL exists, large joule heat is produced at the interface. The produced heat gradually causes the local aggregation of molecules such as dimerization and crystallization of an amorphous HTL. These states then form sites for hole traps and a part of the injected hole carriers builds up a space charge. Simultaneously, the same number

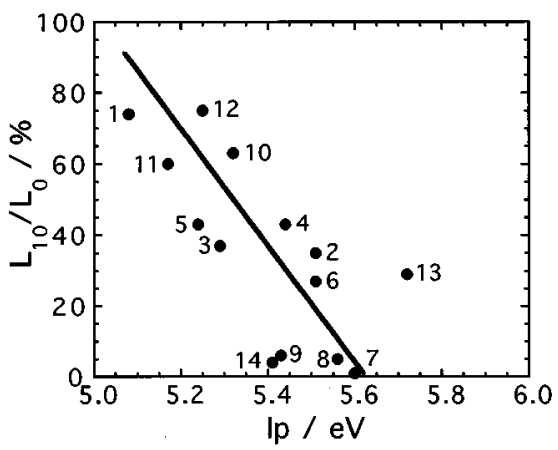

FIG. 2. The relation between the normalized luminance $\left(L_{10} / L_{0}\right)$ and the ionization potential (Ip) of the hole transport layers (HTLs). The numbers in this figure refer to the HTMs listed in Fig. 1. $L_{0}$ : the initial luminance, $L_{10}$ : the luminance after $10 \mathrm{~h}$ of continuous operation. 


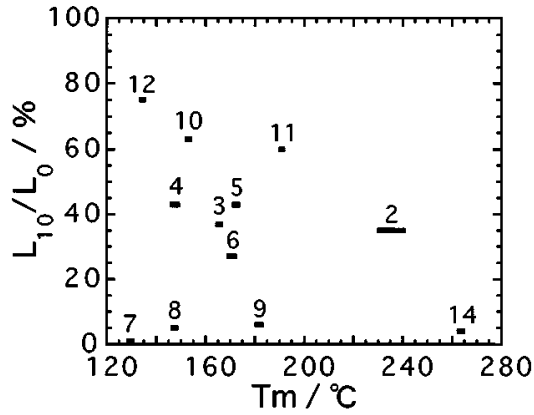

FIG. 3. The relation between the normalized luminance $\left(L_{10} / L_{0}\right)$ and the melting point $\left(T_{m}\right)$ of the hole transport materials (HTMs). The numbers in this figure refer to the HTMs listed in Fig. 1. In the case of the HTM1, a melting point was not observed.

of electron carriers accumulates inside an emitter near the HTL/EML interface, because the HTL has the ability to block electron injection. ${ }^{9}$ In other words, a capacitor is formed in the EL device. These excess electrons interact with the molecular exciton created by the recombination of a hole and an electron at the interface. This leads to the nonradia-

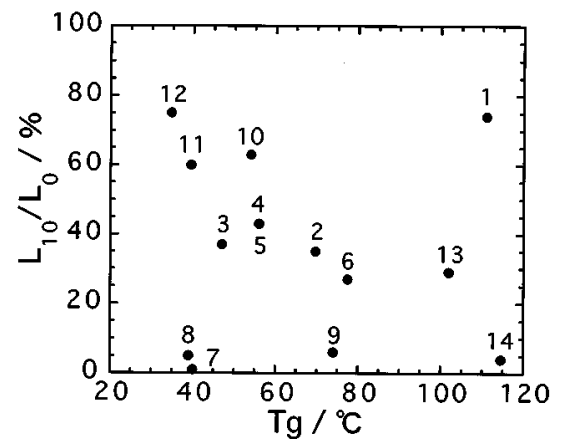

FIG. 4. The relation between normalized luminance $\left(L_{10} / L_{0}\right)$ and the glass transition temperature $\left(T_{g}\right)$ of the hole transport materials (HTMs). The numbers in this figure refer to the HTMs listed in Fig. 1. tive destruction of excitons ${ }^{14}$ and the resulting decrease in luminance.

In conclusion, we elucidated the molecular design of HTMs for obtaining high durability. The formation of small energy barriers between an anode HTL interface was required for high durability. We observed no straightforward relations between the $T_{m}$, the $T_{g}$ of HTMs, and the durability of EL devices. The same way to reduce the energy barrier of electron injection is another important subject for further improvement of organic EL devices. We also must clarify the detailed degradation mechanism.

We would like to acknowledge T. Shimada, M. Sasaki, and M. Ohta for the preparation of hole transport materials.

${ }^{1}$ C. W. Tang and S. A. VanSlyke, Appl. Phys. Lett. 51, 913 (1987).

${ }^{2}$ C. Adachi, T. Tsutsui, and S. Saito, Appl. Phys. Lett. 55, 1489 (1989).

${ }^{3}$ C. Adachi, T. Tsutsui, and S. Saito, Appl. Phys. Lett. 57, 1513 (1990).

${ }^{4}$ C. Adachi, T. Tsutsui, and S. Saito, Appl. Phys. Lett. 56, 799 (1990).

${ }^{5}$ Y. Hamada, C. Adachi, T. Tsutsui, and S. Saito, Jpn. J. Appl. Phys. 32, $1812(1992)$

${ }^{6}$ H. Tokailin, M. Matsuura, H. Higashi, C. Hosokawa, and T. Kusumoto, Proc. SPIE 1910, 38 (1993)

${ }^{7}$ J. Kido, K. Hongawa, K. Nagai, and K. Okuyama, Appl. Phys. Lett. 65, 2124 (1994).

${ }^{8}$ C. Adachi, T. Tsutsui, and S. Saito, Optoelectronics 6, 25 (1991).

${ }^{9}$ C. W. Tang, S. A. VanSlyke, and C. H. Chen, J. Appl. Phys. 65, 3610 (1989).

${ }^{10}$ R. Murayama, T. Wakimoto, H. Nakada, M. Nomura, and G. Sato, U.S. Patent No. 5,227,252 (1993).

${ }^{11}$ R. Murayama, S. Kawami, T. Wakimoto, H. Sato, H. Nakada, T. Namiki, K. Imai, and S. Nomura, Extended Abstracts of the 54th Fall Meeting 1993, Sapporo (The Japan Society of Applied Physics and Related Societies, Tokyo, Japan, 1993), p. 1127.

${ }^{12}$ S. A. VanSlyke, L. C. Roberts, and C. W. Tang, U.S. Patent No. 4,720,432 (1988).

${ }^{13}$ Y. Shirota, Y. Kuwabara, H. Inada, T. Wakimoto, H. Nakada, Y. Yonemoto, S. Kawami, and K. Imai, Appl. Phys. Lett. 65, 807 (1994)

${ }^{14}$ K. C. Kao and W. Hwang, Electrical Transport in Solids (Pergamon, New York, 1981), p. 485 